\title{
Fados y derivas por Lisboa: de la metrópoli colonial a la capital lusófona global
}

\author{
Fado and derives in Lisbon: from the colonial \\ metropolis to the global lusophone city
}

\author{
Edorta Camino Esturo•edorta.camino@ehu.eus \\ UNIVERSIDAD DEL PAÍS VASCO/EUSKAL HERRIKO UNIBERTSITATEA \\ DEPARTAMENTO DE SOCIOLOGÍA Y TRABAJO SOCIAL
}

Recibido: 31-03-2016

Aceptado: 25-05-2016

\section{Resumen}

El presente artículo analiza la realidad multicultural de la ciudad de Lisboa a partir de su pasado histórico colonial y simbólicamente construido. Durante el régimen salazarista, la ciudad se transformó en una alegoría del colonialismo donde se construían monumentos conmemorativos de un pasado imperial y omnilusófono. A través de un análisis documental y de trabajo de campo, la investigación relaciona la actual situación estática y hierática de la ciudad monumental frente al dinamismo de un multiculturalismo urbano cada vez más africanizado, segregado y excluido.

Palabras clave: Colonialismo, multiculturalismo, ciudad global, simbolismo, Lisboa.

\section{Abstract}

This article analyzes the multicultural reality of Lisbon from its historical and colonial past and symbolically constructed. During the Salazar dictatorial regime, the city became an allegory of colonialism where memorials of an imperial and lusophone past were built. Through documentary analysis and field work, this research relates the static and hieratic current situation of the monumental city opposite the dynamism of an increasingly urban multiculturalism, becoming more Africanized, segregated and excluded..

Key words: colonialism, multiculturalism, global city, symbolism, Lisbon. 


\section{INTRODUCCIÓN}

Durante el paso de la historia, las ciudades se transforman según las circunstancias de sus habitantes. El caso de Lisboa es el de una ciudad que fue metrópoli del imperio portugués y ha dado paso a una de las ciudades multiculturales europeas, producto de la historia colonial que lleva a sus urbanas espaldas. Por un lado, se constituye como un lugar de atracción económica para toda la CPLP (Comunidad de Países de Lengua Portuguesa) y, por otro, es su referente simbólico, histórico y cultural.

Un ejemplo de su peso simbólico es la modificación urbanística derivada de la Exposición de 1940 que provocó que, en la actualidad, uno de los lugares de Lisboa más visitados sea el barrio de Belém. La ubicación geográfica de esta área monumental a la entrada del estuario y de la capital del antiguo imperio portugués le confiere una posición estratégica, una especie de "metáfora geográfica" (Foucault, 1979: 116) que evoca el pasado colonial de Portugal y sugieren algunos signos, algunas referencias actuales en la comprensión del simbolismo y el imaginario colonial que desprende la antigua metrópoli de Lisboa.

En esta ciudad global, la continuada inmigración desde las excolonias, principalmente, ha construido una sociedad multicultural. Esta afirmación no quiere decir obligatoriamente que haya una convivencia y un respeto mutuo por las diferentes culturas, sino que la historia colonial y los continuos movimientos de personas de las antiguas colonias a la metrópoli ha ido generando una concentración de diferentes culturas en Lisboa, lo que ha conllevado también una distribución segregada de las mismas en el mapa lisboeta.

El objetivo de este trabajo es analizar la relación entre la simbología colonial de Lisboa con la construcción de una sociedad multicultural y africanizada. Para ello, se realiza a través de una metodología cualitativa, recogida y análisis de datos secundarios, y la realización de trabajo de campo mediante la aplicación de la técnica de la deriva situacionista, principalmente, en diferentes zonas de la ciudad. En este sentido, se ha observado que Lisboa se lusotropicaliza y que su pasado colonial le dota de un reconocimiento emocional e histórico para todo el ámbito lusófono mundial. La ciudad se “africaniza” con la globalización de sus excolonias en un efecto boomerang postcolonial y la inclusión-exclusión de una gran masa social y cultural en sus vidas cotidianas.

\section{EL URBANISMO AL SERVICIO DE LA METRÓPOLI COLONIAL}

“Estudiad a un pueblo fuera de sus ciudades y sólo así lo conoceréis”(Rousseau, 2011: 278).

Lisboa, como capital del imperio colonial, tenía una larga experiencia de "convívio e conflito entre conquistadores e conquistados”. Los vestigios arqueológicos son testimonio de la integración de la ciudad en las rutas comerciales de Fenicios y Griegos, como relataba Estrabón "testemunham a integração de Lisboa nas rotas comerciais dos Fenícios e Griegos” (Fonseca, 2008: 68). Su diversidad cultural histórica concurre también en la época de la expansión del imperio musulmán (Teixeira, 1993), y en sus edificios todavía se puede compro- 
bar algunas de las influencias artísticas y arquitectónicas de ese periodo. En el periodo de la reconquista, paralelo al reinado castellano, “o monarca português garantiu protecção aos muçulmanos (designados mouros forros) que permaneceram na cidade, concentrados num arrabalde edificado no lugar da Mouraria actual” (Fonseca, 2008: 69). La capital portuguesa se convierte en una ciudad cosmopolita, propiciada por el comercio proveniente de las vías marítimas desde diferentes reinados circundantes (Fonseca, 2008: 69).

Según Fonseca, los viajes y este comercio marítimo, así como el ultramarino, "proporcionaram uma grande abertura de Lisboa aos contactos com outros povos e culturas”, volviéndose cada vez más "periférico no contexto europeu e do mundo desenvuelto”. Entre los siglos XV y XVII, fue particularmente relevante la llegada de un "elevado número de es cravos africanos, estimando-se que, no período da dominação filipina, representariam cerca de 10\% dos habitantes da cidade” (Fonseca, 2008: 70).

Para los extranjeros que llegan a su puerto y desembarcan junto con todo tipo de mercancías, Lisboa representa una especie de "puerta” de lo exótico, un lugar donde se pueden encontrar especies de frutas y animales completamente desconocidas en otros países (una de las atracciones turísticas por excelencia de entonces era el mercado del pescado...) y cuya población está compuesta, sorprendentemente, por una gran cantidad de gente de color, tanto esclavos como siervos de mercaderes y nobles (Fraticelli, 2001: 278).

Lisboa se convierte en una metrópolis de referencia, caracterizada por ser "un mito, una historia, un relato que nos ayuda a algunos de nosotros a encontrar nuestro hogar en la modernidad" (Soja, 2008: 117). Pero, a su vez, la metrópolis representa "la alegoría de la crisis de la modernidad”. En este sentido, Petit se refiere a la representación de la ciudad y plantea el espacio urbano como un "hecho cultural e histórico, ámbito de convivencia, de arraigo, donde es importante la representación urbana que llegan a tener los ciudadanos del lugar en el que viven, pues muchos de ellos viven alojados en los contenedores arquitectónicos que llenan las nuevas metrópolis sin habitarlos existencialmente” (Petit, 2014: 13). El imaginario de estas metrópolis contiene unas "narrativas surgidas de la experiencia subjetiva y colectiva de la ciudad, experiencia que no sólo es lingüística sino también visual y física” (Petit, 2014: 16).

Chambers (1990) expone que "ir más allá de estas sombrías historias del exilio, y de ese gris y lluvioso país del alma angustiada implica establecer un sentido de pertenencia en la ciudad y hacer de la tradición un espacio de transformación, más que la escena de un destino poco alentador", porque "la metrópolis no es simplemente la etapa final de una narrativa conmovedora, del Apocalipsis y de la nostalgia, también es el lugar de las ruinas de los órdenes previos en las cuales diferentes historias, lenguajes, memorias y trazos se entretejen y recombinan continuamente en la construcción de nuevos horizontes” (Soja, 2008: 117). David Harvey (1988) explora los límites de la ciudad contemporánea y reconoce que posee "muchos estratos”, como si de un "palimpsesto" se tratara. La ciudad es "un paisaje amalgamado conformado por diversas formas edificadas que, con el paso del tiempo, se superponen unas sobre otras”. Para Harvey: 
En algunos casos, las primeras capas tienen un origen verdaderamente antiguo que data de las primeras civilizaciones, cuya huella aún puede distinguirse debajo del actual tejido urbano. Pero incluso ciudades relativamente actuales encierran capas particulares que se han ido acumulando en las diferentes fases de transformación, en el caótico crecimiento urbano engendrado por la industrialización, la conquista colonial, la dominación neocolonial, oleada tras oleada de cambio especulativo y modernización. En los últimos doscientos años, las capas parecen haberse acumulado en mayor medida y más rápidamente, en respuesta al rápido y creciente incremento de la población, el fuerte desarrollo económico y el poderoso cambio tecnológico (Citado en Soja, 2008: 177).

El estudio clásico de Henri Lefebvre (1974), La producción del espacio, aporta una base conceptual para constituir el discurso del imaginario universalista de la ciudad como no neutral y, en esta no neutralidad, se establecen una serie de elementos que legitiman muchos de los desequilibrios que aparecen en la ciudad. Así mismo, la existencia de un espacio neutral delataría un orden que establecería unas normas y unas actitudes dogmatizadas por ese discurso hegemónico. Una idea adecuada a nuestro tema es que, para Lefebvre, "el espacio ha sido siempre político pero ahora lo es más que nunca” (1974: 222).

En Lisboa, a mediados del siglo XIX, se llevó a cabo una planificación urbanística del espacio litoral, junto a la desembocadura del río Tejo, en la zona del barrio de Belém. La fecha era significativa, ya que en 1940 se conmemoraban dos efemérides históricas, en 1140 se produjo la formación del reino de Portugal y en 1640 se proclamaba la independencia portuguesa del reino de Castilla (Elias, 2010: 5), La intención era construir un nuevo puerto que le devolviese a Lisboa "o esplendor e a importância perdidos, transformando-a novamente na cidade-portuária por excelência, não o primeiro emporio do mundo, como quando arrancou das mãos de Veneza as chaves com que a rainha da Adriatico abria as portas da Europa ás mercadorias do oriente; mas sim um dos principaes emporios europeus dos generos coloniaes”. Para ello, se comenzaron a elaborar proyectos urbanísticos para "os melhoramentos e aformoseamento de Lisboa, nos finais do século XIX e primeiros décadas do XX” (Barata, 2009: 2).

Para "mostrar" los "caminos del imperio" a los portugueses y a ese $10 \%$ de esclavos africanos y africanas llegados a Lisboa, el Estado Novo organizó diferentes "manifestações patrióticas, como colóquios, publicações, prémios literários, concursos escolares, cortejos e comemorações, exposições para públicos adultos ou jovens, que procuravam mobilizar a opinião pública para o projecto colonial, que levava a civilização ao continente africano, consolidando a grandeza da Nação” (Leite et al., 2013: 36). Estas manifestaciones de exaltación patriótica llegaron a un momento culmen con la organización de la Exposição do Mundo Português, en 1940.

La exposición fue realizada en el espacio comprendido entre el Monasterio de los Jerónimos y la Torre de Belém. En este lugar, también hubo lugar para exponer el mundo africano. El Jardim Colonial, actualmente denominado Jardim Tropical, fue usado como parque temático para exponer las “aldeias” africanas con personas reales. Según Oscar Lopes (2007), 
las condiciones de instalación eran tan precarias que "os negros morriam como tordos de pneumonia” (Citado por Leite et al., 2013: 36). Leite afirma que estos escenarios ficticios eran "Jardins zoológicos humanos", con el espectáculo de ver a ciudadanos africanos semidesnudos, con una actitud pasiva, "sempre sem fazer nada, dedicando-se apenas às futilidades”, procurando ofrecer una imagen poco civilizada para el espectador blanco y europeo (Leite et al., 2013: 37).

Según Leite, la población portuguesa podría contactar directamente con los pueblos africanos, observar sus comportamientos y costumbres "primitivas", "legitimando o esforço civilizador português e admirando o exotismo destas novidades", al mismo tiempo que muchas otras actividades que se realizaban intentaban conseguir la inferiorización y "ridicularização do africano contribuíam para consolidar a sua desvalorização racial, cultural, social” y tratar de difundir en Portugal una imagen banal sobre los “assimilados”, a través de "jornais, bandas desenhadas, anúncios, uma vasta produção iconográfica, destinada a todos os portugueses, crianças, jovens e adultos”. En este contexto, la población portuguesa que tenía una "intimidade secular com os africanos, marcada pelo preconceito somático (o preto) e social (o escravo), viu-se confrontada com uma nova visão destes homens e mulheres diferentes, onde o reforço do negativo era legitimado pelo poder político e pela ciencia” (Leite et al., 2013: 38).

Leite expone que la evolución arquitectónica de la ciudad era también utilizada para reforzar la acción colonial y la idea imperial del Estado Novo:

As grandes avenidas na zona norte da cidade, as casas mais faustosas dos "africanistas” pagas com o cacau de São Tomé - na gíria o cacau significava o dinheiro, o Bairro da Colónias, bairro modernista, construído a partir dos anos 30 numa das encostas da colina da Graça, no loteamento duma antiga quinta, que devia lembrar aos portugueses o seu império “de Minho a Timor”, constituem as novidades urbanas do século XX salazarista. Sublinhe-se igualmente o reforço grandioso de Belém, dos Jerónimos e das margens do Tejo pontuadas pela Torre de Belém e pelo Monumento aos Descobrimentos Portugueses. Avenidas novas e novas construções, mas também a Casa dos Estudantes do Império, autorizada em 1944 pelo regime para acolher os estudantes “africanos”, brancos, pretos ou mestiços, que se tornou num espaço de contestação ao colonialismo, vindo a ser encerrada em 1965 (Leite et al, 2013: 39).

Para Helena Elias, el objetivo era proporcionar un escenario histórico nacional para celebrar las conmemoraciones oficiales del Estado Novo en el año 1940. Se festejaban estos hechos históricos para inculcar a las masas la "devoção pela pátria e a confiança no novo governo. Belém reunia à partida dois monumentos nacionais aos quais se podia associar uma Exposição que mostrasse o vigor da nova força política - Estado Novo, ombreando com os feitos do pasado" (Elias, 2004: 52). 


\section{LA SIMBOLOGÍA COLONIAL DE BELÉM: UNA MEMORIA HISTÓRICA DEL COLONIZADOR}

La modificación urbanística derivada de la Exposición de 1940 provocó que, en la actualidad, uno de los lugares de Lisboa más visitados turísticamente sea el barrio de Belém. La ubicación geográfica de este área monumental a la entrada del estuario y de la capital del antiguo imperio portugués le confiere una posición estratégica, una especie de "metáfora geográfica” (Foucault, 1979: 116) que sugiere un saludo de despedida y bienvenida a todas aquellas naves que partieron rumbo a la inmensidad oceánica de un mundo supuestamente hecho para la conquista, la cristianización y la apropiación de todas sus riquezas de mano de una "nación cosmopolita, destinada a la vida comercial, marítima y colonizadora" (Costa, 1966: 61).

En este espacio tan reducido del barrio de Belém, además se concentran esos otros atractivos histórico-turísticos, mencionados anteriormente, construidos durante el siglo XX, que sugieren algunos signos, algunas referencias actuales en la comprensión del simbolismo y el imaginario colonial que desprende la antigua metrópoli de Lisboa. Entre ellos, se encuentran el Monumento a los Descubrimientos (Padrão dos Descobrimentos) siendo un mausoleo conmemorativo al Infante Don Henrique o Enrique el Navegante; la Plaza Imperio, una plaza situada en frente de los Jerónimos; el Jardín Tropical o Jardim-Museu Agricola Tropical o Jardim de Ultramar y el Museo de Etnología, situado a poca distancia de los anteriores (Figura 1).

El Monumento a los Descubrimientos (Figura 2) es una escultura gigantesca de mármol y representa, en parte, el momento en que "Portugal inició sus expediciones en navegación de cabotaje por la costa atlántica del continente africano en busca de un camino marítimo expedito hacia las Indias” más seguro que el de la ruta de la seda. Esta empresa fue planificada y ejecutada por el Infante don Enrique el Navegante (De las Casas, 1989).

Figura 1. Distribución de la estatuaria en la zona turística-colonial de Belém

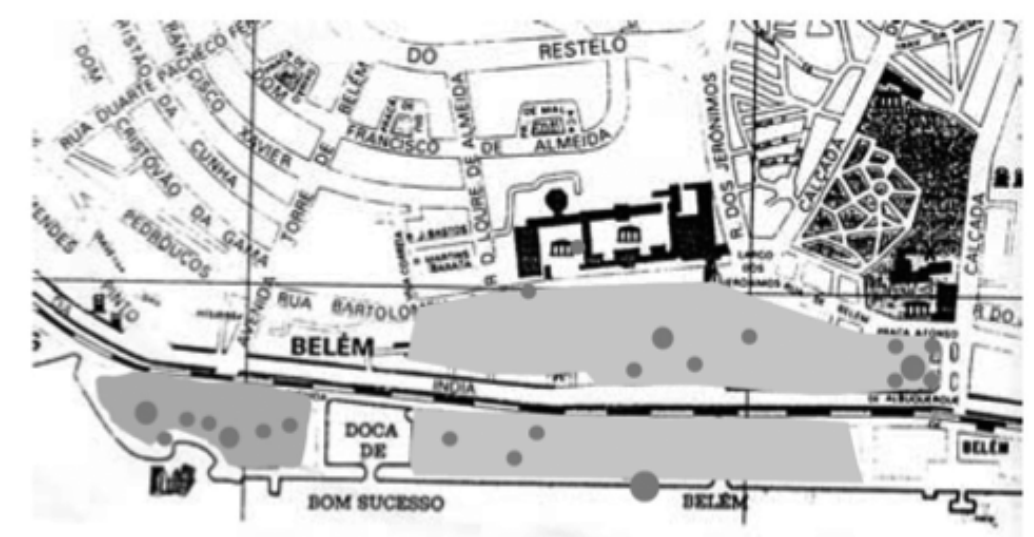

Fuente: Elias (2004). 
Figura 2. Monumento a los descubrimientos

Fuente: Elaboración propia.

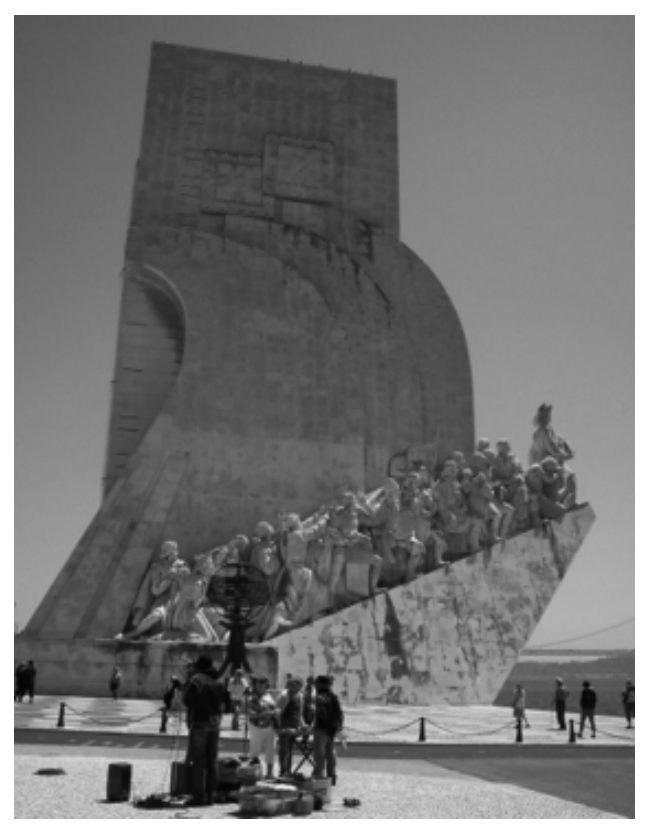

En la "cubierta” de la nave, se encuentran 33 personajes, incluyendo al Infante D. Henrique. Entre ellos, la madre del propio infante, única mujer digna de ocupar un lugar entre los elegidos descubridores. La función descubridora era desigual en cuanto al género, salvo que fuera una componente de la realeza portuguesa. Ella se llamaba Doña Filipa de Lencastre y ocupa uno de los últimos lugares en la popa de la carabela. Con gesto hierático y acompañado por el Infante D. Pedro, hermano del Navegante, reza de rodillas por la suerte de la tripulación. En la misma, se encuentra el séquito compuesto por diferentes oficios y otros menesteres. Principalmente son navegantes, contándose trece con el Infante D. Henrique y Vasco de Gama, dos capitanes, dos pilotos, un matemático, un cosmógrafo, un viajero, un pintor, un poeta, un misionero, un franciscano, un dominico, un gobernador, dos infantes más y un rey.

Posiblemente no sea por azar, la quilla de la carabela del Infante don Henrique y los descubridores apunta directamente hacia África. Una gran brújula dibujada en el suelo de la plaza aledaña orienta la nave ligeramente dirección sur-sudeste, ¿acaso subyace un "mensaje para navegantes” que apunta directamente a las colonias y a los colonizados? ¿anuncia un nuevo tiempo de conquistas? Como veremos más adelante, en los años en los que se erigió el monumento, las colonias africanas comenzaron a despertar de su sueño colonial.

Esa rosa de los vientos de 50 metros de diámetro dibujada en el suelo fue un regalo de Sudáfrica en 1960. El planisferio central, adornado con dibujos de galeones y sirenas, tiene 14 metros y muestra las rutas de los descubridores en los siglos XV y XVI. Los descubrimientos portugueses mostrados allí, son los siguientes -agrupados por orden cronológico-:

1418 Madeira, 1427 Azores, 1434 Cabo Bojador, 1444 Cabo Verde, 1460 Guinea, 1471 Mina, 1475 Santo Tomé y Príncipe, 1483 Congo, 1483 Angola, 1488 Cabo de Buena Esperanza, 1497 Natal, 1498 Quelimane, 1498 Calcuta, 1500 Madagascar, 1500 Terra Nova, 1500 Porto Seguro, 1502 Cananea, 1505 Ceilán, 1507 Ormuz, 1509 Damao, 1509 Malaca, 1511 Pegu, 1512 
Molucas, 1512 Timor, 1514 Río de la Plata, 1514 Río de Cantón, 1516 Río Ganges y 1525 Islas Palaos

Em frente da Praça do Império, o monumento ao Infante D. Henrique foi igualmente um dos elementos mais emblemáticos da referida exposição: concebido em materiais efémeros, foi posteriormente reconstruído em pedra e inaugurado em 1960. Com a inauguração deste monumento, o Estado Novo inaugura o processo de legitimação de Belém como espaço de representação da nação, configurando o local muito próximo do que hoje se conhece. Posteriormente em Belém, o estado foi afirmando a vocação simbólica do lugar (Elias 2004: 52).

El Monumento a los Descubrimientos contiene toda la iconografía propia del proyecto de dominación del Imperio colonial. No sólo supone la alegoría del “descubrimiento” de África para el enriquecimiento y el orgullo de la corona portuguesa, sino también el comienzo de su pérdida. De un mismo modo, representa la colonización y la descolonización de las colonias africanas. Se trata de una escultura situada en un lugar público para facilitar el acceso a todas aquellas personas que quieran admirarla y, a su vez, naturalizar la memoria colonial que su imagen manifiesta y que sea capaz de "moldear identidades comunes" que ayuden a "legitimar a regentes o procesos históricos controvertidos" (Knippschild, 2004: 57). Abreu (2005) se refiere a esta escultura pública como un polo de "diferenciação", lo que le identifica como una escultura que intenta

inculcar ou contaminar, isto é, têm a capaci-dade de "fazer ressoar" valores, imagens ou símbolos de um determinado grupo, que se pretendem inscrever numa dada colectividade, cabendo-lhes, assim se espera, o papel de veicular mensagens ou ícones destinados a vincar distinções (sociais, religiosas, ideológicas, rácicas) nessa co-lec-tividade, visando a sua imposição, acei-tação e assimilação por parte da mesma, e por isso a sua in-ten-cio-na-lidade apre-senta-se como diferenciadora (Abreu, 2005: 53).

En esta línea crítica, Mbembe expresa que

lo que, paradójicamente, nos enseñan la colonización y sus reliquias, es que la humanidad del hombre no viene dada: se crea. Y no se debe ceder ni un centímetro en la denuncia de la dominación y la injusticia, especialmente cuando ésta se comete por ella misma -en la era del fratricidio, es decir, esta época donde el potentado poscolonial no propone otra cosa que la evidencia desnuda de una existencia descarnada. Así pues, no podemos menospreciar lo simbólico y político de la presencia de estatuas y monumentos coloniales en los lugares públicos africanos (Mbembe, 2008: 5).

En este caso, el lugar público es una gran plaza europea con un alto contenido colonial que cualquier ciudadano y estudiante africano o africana puede contemplar en la visita a la metrópoli histórica, aquella por la que fue colonizado.

Mbembe, en un contexto africano posterior a la colonización, se pregunta qué hacer ante estos monumentos, y propone que en cada país africano se proceda inmediatamente a una recolección tan minuciosa como posible de las estatuas y monumentos coloniales. Que se reúnan en un único parque, que servirá al mismo tiempo de museo para las generaciones futuras. Este parque-museo panafricano se usará como sepultura simbólica al colonialismo 
de este continente. Una vez realizado el entierro, que nunca más nos sea permitido utilizar la colonización como pretexto para justificar nuestras actuales desgracias. Asimismo, prometamos igualmente dejar de erigir estatuas, sea a quien sea. Y que, al contrario, florezcan por todos lados bibliotecas, teatros, talleres culturales, en definitiva, todo lo que alimentará la creatividad cultural del mañana (Mbembe, 2008: 5).

En este sentido, Fanon critica un "mundo dividido en compartimentos, maniqueo, inmóvil, mundo de estatuas: las estatuas del general que ha hecho la conquista, la estatua del ingeniero que ha construido el puente. Mundo seguro de sí, que aplasta con sus piedras las espaldas desolladas por el látigo. He allí el mundo colonial” (Fanon, 1999: 40).

\section{MULTICULTURALIDADES LUSÓfONAS EN UNA CIUDAD GLOBAL}

Lisboa es una de las grandes ciudades del mundo, una ciudad global, caracterizada por una clasificación Beta+ en el ranking mundial del 2012, analizado por el GaWC (Globalization and World Cities Research Network), creado por el Departamento de Geografía de la Loughborough University en el Reino Unido.

Saskia Sassen acuñó el concepto de ciudad global o global city en 1991, en función de unas características económicas, culturales y geopolíticas, según las cuales las ciudades se interrelacionan y adquieren unos protagonismos en la escena mundial. Lisboa se sitúa en una posición estratégica en el arco atlántico del sur de Europa. Para Sassen, las grandes ciudades de todo el mundo son "el terreno adecuado para que una multiplicidad de procesos de globalización asuman formas concretas y localizadas”, provocadas por la globalización. Las global ciy también concentran "una cuota cada vez mayor de poblaciones desaventajadas", es decir, de ciudadanos y ciudadanas que viven en condiciones cada vez más miserables, que se han convertido en "un terreno estratégico para toda una serie de conflictos y contradicciones” de la globalización del capital. En las ciudades "los marginados han hallado su voz y también están reclamando a la ciudad” (Sassen y Pérez, 2007: 18).

Estas presencias conjuntas han convertido a las ciudades en un terreno disputado. La ciudad global concentra la diversidad. Sus espacios se inscriben en la cultura corporativa dominante, pero también mantiene una multiplicidad de otras culturas e identidades, especialmente a través de la inmigración. El distanciamiento resulta evidente: la cultura dominante solo puede abarcar una parte de la ciudad. Y aunque el poder corporativo identifica las identidades y culturas no corporativas con lo «otro», devaluándolas por tanto, estas están presentes en todas partes (Sassen y Pérez, 2007: 19).

Según Sassen, actualmente "las ciudades globales son en parte los espacios del poscolonialismo y, de hecho, cuentan con condiciones para la formación de una teoría poscolonialista”. Sassen lo argumenta por la "diversidad" que se concentra en las ciudades occidentales actuales, donde sus espacios están "inscritos en la cultura empresarial dominante, pero también en una multiplicidad de otras culturas e identidades”. El poder devalúa estas iden- 
tidades inscribiéndolas en la "otredad", "la cultura dominante puede abarcar solo una parte de la ciudad” (Sassen, 2007: 42), pero aún así están muy presentes en la ciudad, en sus barrios marginales e, incluso, compartiendo espacios de los barrios financieros o residenciales. Según Sassen, "una inmensa diversidad de culturas de todo el mundo, cada una de ellas arraigada en un país o pueblo particular, se ven reterritorializadas en unos pocos lugares” de las global city más importantes.

Con demasiada frecuencia la inmigración y la etnicidad se constituyen como «otredad». Al entenderlas como un conjunto de procesos en virtud de los cuales se localizan elementos mundiales, se constituyen mercados laborales internacionales y se desterritorializan culturas de todo el mundo, las situamos ahí mismo, en el centro del escenario, junto con la internacionalización del capital, como aspecto fundamental de la mundialización actual. Además, esa forma de narrar los acontecimientos migratorios de la era de la posguerra refleja perfectamente la influencia permanente del colonialismo y las formas poscoloniales de imperio en los más importantes procesos de la mundialización actual y, concretamente, los que vinculan a los países de emigración y los de inmigración. Si bien la génesis y el tenor concretos de su responsabilidad varían según los casos y los períodos, ninguno de los más importantes países de inmigración son espectadores inocentes (Sassen, 2007: 42).

En Lisboa, la inmigración ha construido una sociedad multicultural. Esta afirmación no quiere decir obligatoriamente que haya una convivencia y un respeto mutuo por las diferentes culturas, sino que la historia colonial y los continuos movimientos de personas de las antiguas colonias a la metrópoli ha ido generando una concentración de diferentes culturas en Lisboa, lo que ha conllevado también una distribución segregada de las mismas en el mapa lisboeta. Esos acontecimientos migratorios eran reducidos hasta los años 60, ya que "las necesidades de mano de obra estaban satisfechas y el contexto político y de subdesarrollo conformaban un panorama poco atractivo tanto para la inversión como para la inmigración, por el contrario, se hablaba de emigración”. Con el fin de la década, la situación comenzó a variar por dos factores, el desarrollo industrial y la reducción de la población masculina debido a la guerra colonial. De este modo, comenzó a producirse una necesidad de mano de obra y se produjo una inmigración desde Cabo Verde, en un principio, una población no considerada como extranjera, ya que eran "población oriunda del Imperio" y la mayoría "fijó su residencia en la zona portuaria, en S. Bento, el tradicional centro de Lisboa” (Vasconcelos, 2003: 3). Los “extranjeros” europeos, en cambio, se asentaron en el interior de la ciudad o en las zonas de "prestigio" de la costa (Estoril y Cascais), comenzando a desarrollarse una "segregación territorial que se desarrollará más tarde con la llegada masiva de población oriunda de las ex colonias” entre los años 1975 y 1976, con el proceso de descolonización (Vasconcelos, 2003: 4). En este periodo retornaron al país entre 500.000 y 700.000 personas. Los “retornados” estaban divididos en tres grupos: "la comunidad blanca portuguesa, que habitaba en las antiguas provincias ultramarinas; los “naturalizados”, que eran los ciudadanos de las colonias que rápidamente pidieron la naturalización al abrigo de acuerdos entre la metrópoli y las colonias, acuerdos que se extinguieron poco tiempo después; y, por último, los mismos ciudadanos que hasta Junio de 1975 eran "población del imperio” y que, en esta fecha, pasaron a ser extranjeros”. 
Esto conllevó a un cambio en las estadísticas sobre inmigración en pocos años con una africanización de la inmigración:

Figura 3. Población extranjera en la Región Metropolitana de Lisboa (1960-1981)

\begin{tabular}{|c|c|c|}
\hline & 1960 & 1981 \\
\hline Porcentaje de extranjeros en Portugal & 1,0 & 1,8 \\
\hline Concentración en la RML ( RML / país) & 55,2 & 44,5 \\
\hline $\begin{array}{c}\text { Concentración en la ciudad de Lisboa } \\
\text { (ciudad / RML) }\end{array}$ & 72,8 & 33,5 \\
\hline Europeos en el conjunto de extranjeros & 84,2 & 28,2 \\
\hline Africanos en el conjunto de extranjeros & 0,9 & 60,5 \\
\hline
\end{tabular}

Fuente: Vasconcelos (2003).

La académica María Lucinda Fonseca nos muestra gráficamente la evolución de la inmigración extranjera total a Portugal desde 1975 hasta 2006:

Figura 4. Evolución del número de extranjeros documentados en Portugal (1975-2006)

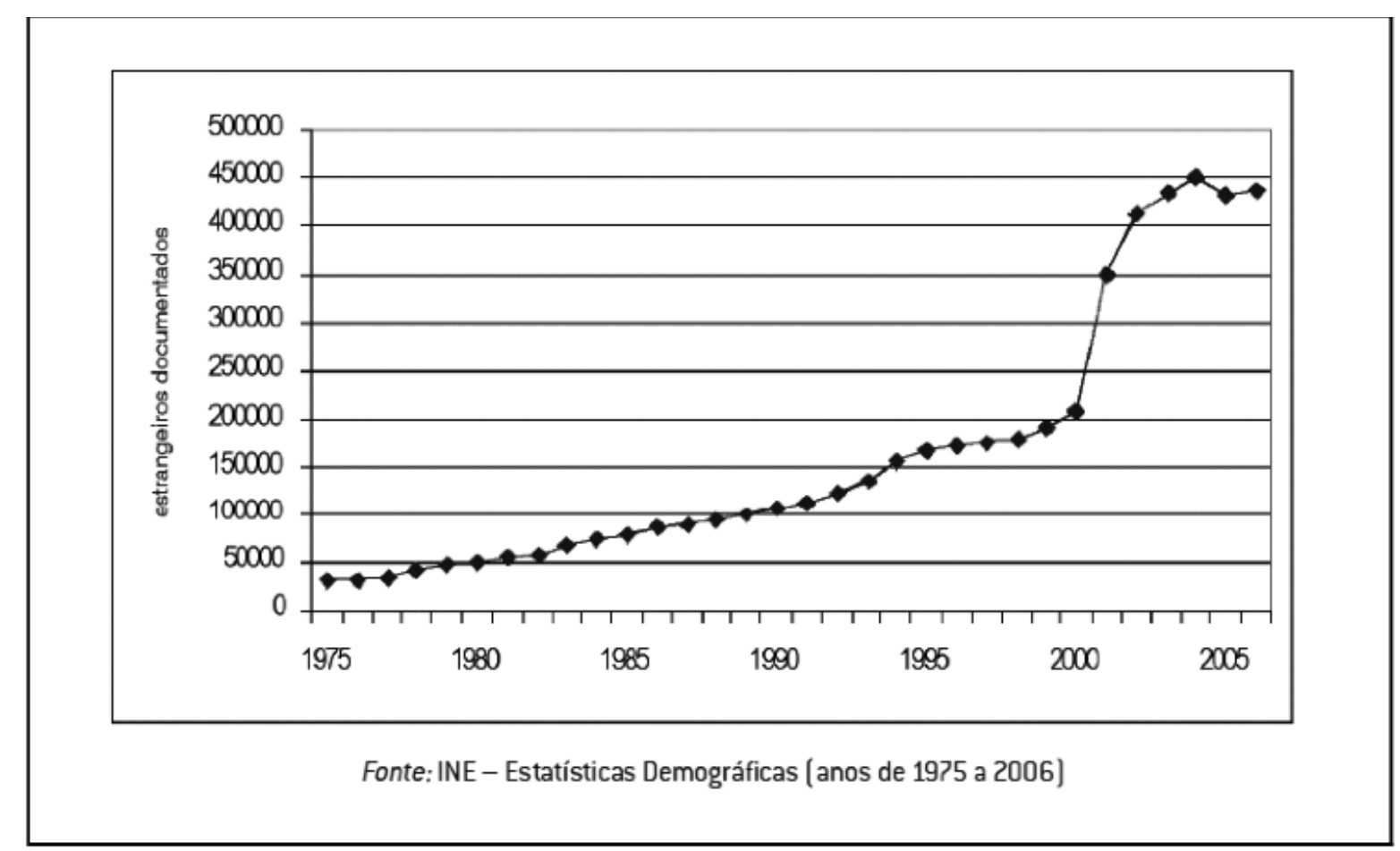

Fuente: Fonseca (2008).

Así como la variación de la inmigración en Portugal desde 1960 hasta 2006 y su distribución por países: 
INGURUAK [60] | 2016 | 71-86

Fados y derivas por Lisboa: de la metrópoli... | Edorta Camino Esturo

Figura 5. Extranjeros residentes en Portugal, en 1960, según la nacionalidad.

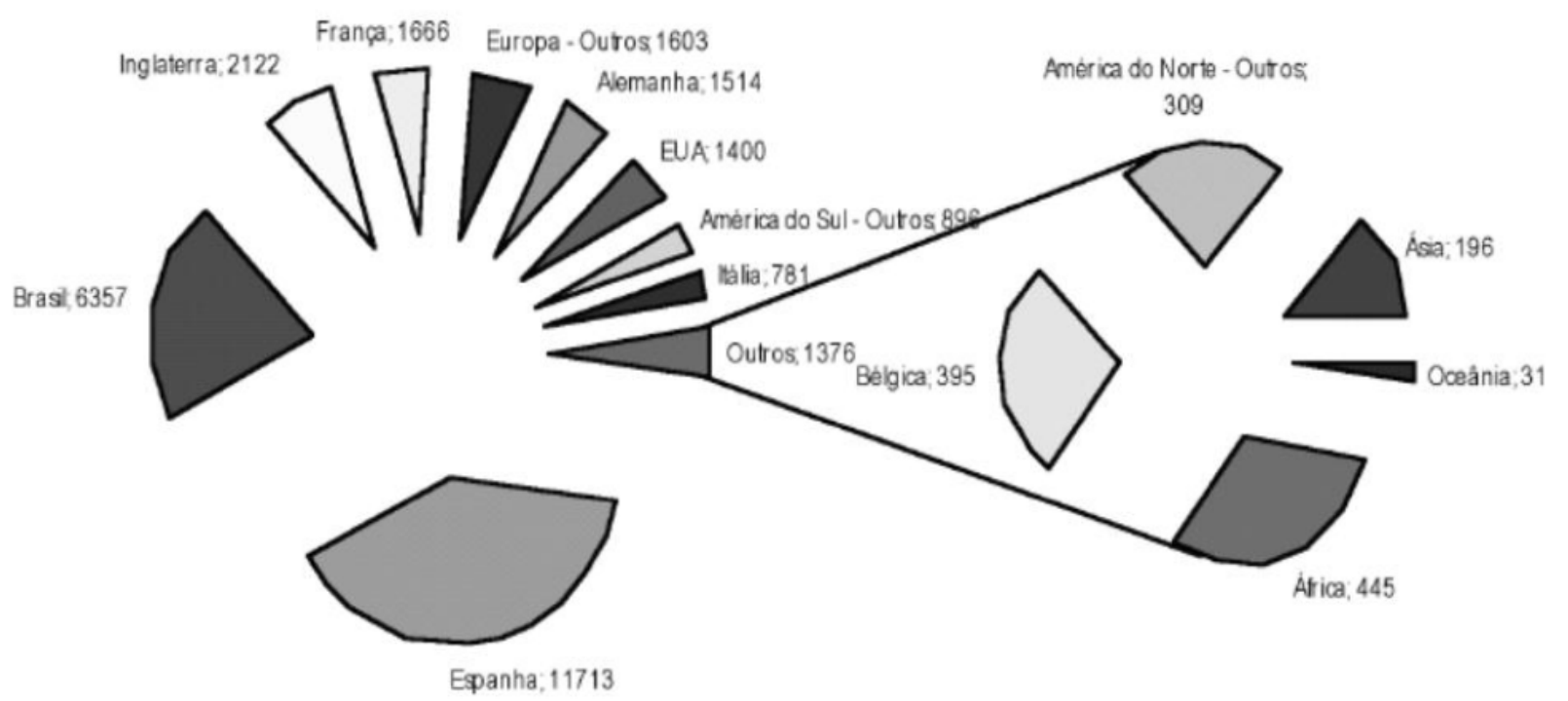

Fonte: INE - Recenseamento Geral da População, 1960

Fuente: Fonseca (2008).

Figura 6. Extranjeros documentados, registrados en Portugal en 2006, según nacionalidad.

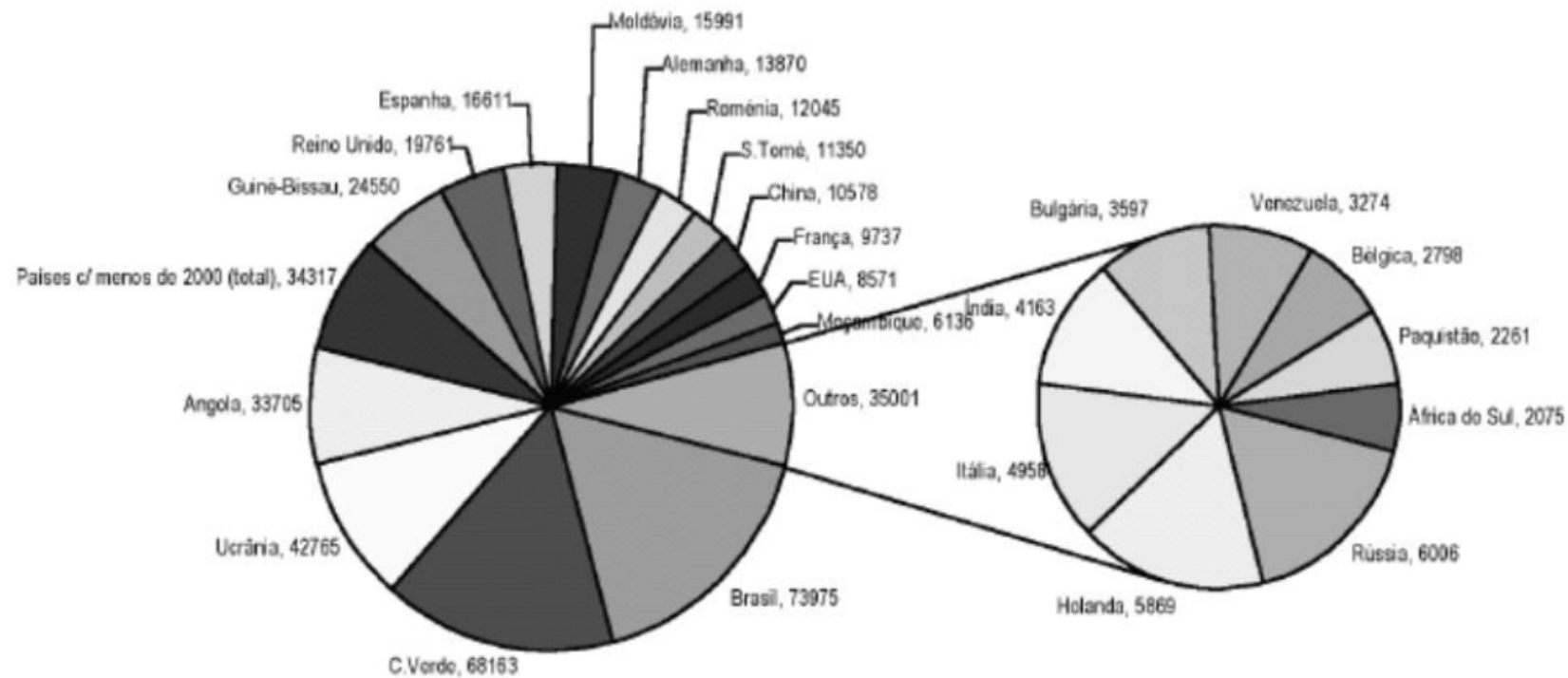

Fonte: INE - Estatísticas demográficas 2006 [tratamento próprio]

Fuente: Fonseca (2008).

A nivel global, el país de origen de la inmigración a Portugal en 2006 estaría distribuida de la siguiente manera: 
Figura 7. Mapa de la cantidad de ciudadanos extranjeros documentados, residentes en Portugal, según su nacionalidad (2006)

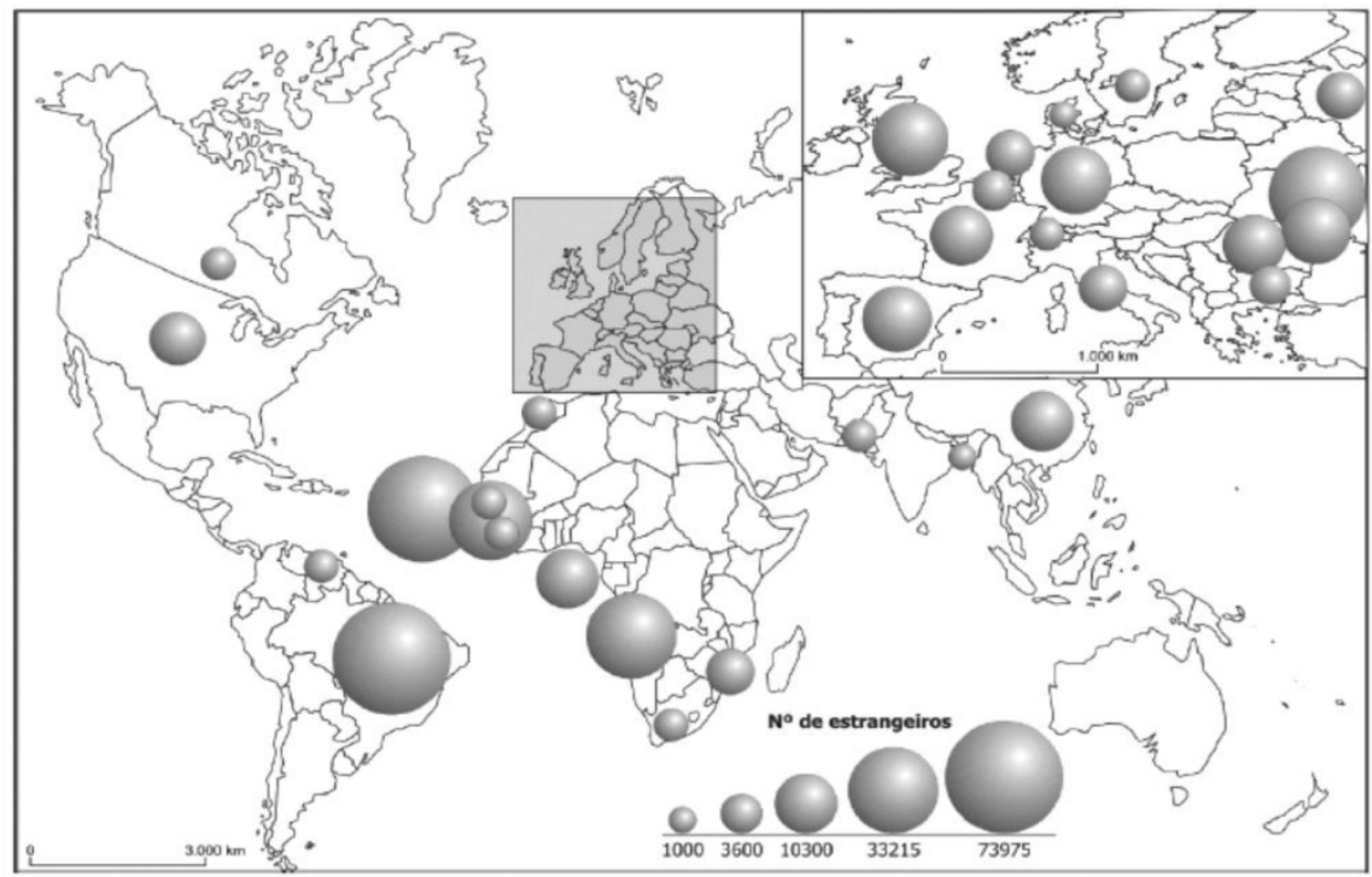

Fuente: Fonseca (2008).

Estos gráficos muestran objetivamente los cambios producidos en las inmigraciones, pero habría que señalar también las consecuencias humanamente adversas de la mayor parte del proceso migratorio a la ex-metrópoli, aquella "ciudad matriz" enriquecida por los ingresos proporcionados desde las colonias africanas. A pesar de ello, la población africana se encontró “sin apoyo al llegar a Portugal”, lo que, añadido a la pobreza de sus países de origen, tuvieron que instalarse en "barrios clandestinos" en los extrarradios de la ciudad, construyendo viviendas infrasaludables. Con el final de la dictadura y la internacionalización de la economía portuguesa, se produjo una entrada de inmigración europea y norteamericana como profesionales cualificados. Al mismo tiempo, el aumento de la construcción aportó "más mano de obra proveniente sobretodo de los PALOP y no cualificada”. Esta dicotomía produjo una segregación espacial ya que se realojó de forma “concentrada” a grupos de población africano, con bajos ingresos en barrios de la periferia (Vasconcelos, 2003: 5).

Esta segregación espacial provocó que estos barrios fueran adquiriendo una sintomatología social conflictiva por las condiciones socioeconómicas en las que se encontraban. Esta situación fue creando una representación de los inmigrantes y de las minorías étnicas de estos barrios como fuente de conflicto por el resto de la población del Área Metropolitana de Lisboa, lo que desarrolló una “etnificación del conflicto” y una imagen social negativa de esas minorías. Para Malheiros, "esta visão etnicizada dos espaços de conflito e daqueles que aí residem é indissociável da existência de fenómenos de estigmatização dos espaços e 
dos grupos nele residentes (vistos como violentos, anti-sociais...), bem como de práticas de discriminação, tanto quotidiana, como institucional” (Malheiros et al, 2007: 2), ya que este tipo de conflicto de base étnica está asociado a un lenguaje político y de los mass media que originan unos "enclaves polarizados, onde reside essencialmente população oriunda dos PALOP” (Malheiros et al, 2007: 4). Para Daniel Malet, "la construcción periodística de la imagen de los luso-africanos, sobre todo a través de la prensa durante el proceso de regularización de inmigrantes de 2001, proyecta a un africano ocioso y holgazán para con el trabajo, aunque también explotado por sus patrones, aprovechándose de su situación administrativa irregular. Los barrios lata del área metropolitana donde viven muchos de ellos, tienen fama de inseguros y peligrosos, y se perciben como una auténtica lacra para el país, en contraste con los nuevos inmigrantes provenientes del este de Europa” (Malet, 2007: 7).

Según Macagno (2003), las ciudades de las antiguas metrópolis se han convertido en el escenario de un nuevo "contacto colonial”, en el cual”as peripécias da globalização agregam um elemento mais complexo à modernidade pós-colonial”. En este sentido, Macagno expone que, actualmente, los antiguos "súbditos” no son portadores de una cultura "unívoca, exótica e irredutível ao mundo occidental”, sino que comparten identidades culturales polisémicas y heterodoxas, además de caracterizarse por su bilingüismo o multilingüismo, cuestiones estas que "acompanham estes novos nômades da modernidade pós-colonial- (Macagno, 2003: 4).

\section{CONCLUSIONES}

La ordenación de la ciudad de Lisboa no obedece solamente a unas estrategias urbanísticas y de gestión territorial, sino también a una representación del poder y la expresión de la mentalidad colonial que se aprecia en las calles de Lisboa. Los diferentes elementos arquitectónicos que se construyeron son testimonio de un pasado colonial que refleja actualmente la diversidad cultural y social de Lisboa en torno a la africanización de su población inmigrante. En este sentido, la investigación ha mostrado algunas evidencias sobre esta producción social de la ciudad en torno a intereses políticos y simbólicos que relacionan el ideario colonial estático con el carácter dinámico y global de las nuevas realidades socio-culturales en Lisboa, estableciendo una situación paradójica y algo melancólica (relacionada con la saudade) que acompaña a la sociedad lisboeta, en ocasiones.

Durante el Estado Novo del régimen salazarista, la ciudad se transformó en un espejo de la colonialidad del imperio portugués. El barrio de Belém, a orillas del estuario del río Tejo, presenta una simbología de este pasado colonial manifestada en las diferentes formas artísticas y urbanísticas que se ubican en este lugar. Una de estas manifestaciones, el Monumento a los descubrimientos, es una apología de la conquista y la dominación de los pueblos africanos. La escultura monumental representa una carabela, en cuya cubierta aparecen las figuras de los descubridores que hace cinco siglos tomaron los “caminhos do mar" para civilizar y cristianizar a los pueblos sin "evolucionar”. Los africanos y africanas se encuentran en Lisboa con esta memoria histórica de aquellos tiempos de dominación física y mental en sus cuerpos e identidades africanas actuales. 
Lisboa se ha convertido en una ciudad global (Sassen, 1999), en un espacio postcolonial (Sassen y Pérez, 2007) en el que se establece una multiplicidad de culturas y, por lo tanto, de cosmovisiones diferentes. La peculiaridad es que esta multiculturalidad es ampliamente lusófona, debido a ese pasado común histórico que ha sido un efecto llamada para los países de las antiguas colonias portuguesas, principalmente. Durante años, la inmigración mundial a Lisboa ha provocado que estas masas migratorias se concentren y segreguen en unas zonas concretas de la ciudad, produciendo guetos, los cuales son percibidos como conflictivos y esto origina una discriminación racial de lo africano (Malheiros et al, 2007).

\section{BIBLIOGRAFÍA}

Andreottti, L. y Costa X. (eds.) (1996). Teoría de la Deriva y otros textos situacionistas sobre la ciudad. Barcelona: Actar.

Barata, A.M. (2009). A ordenação do espaço litoral de Lisboa, 1860-1940. Scripta Nova, Vol XIII, $n^{\circ} 296(4)$.

Costa, M.F. (1965). As missoes católicas portuguesas e o ensino no Ultramar. Boletim Geral do Ultramar, Vol, XLI - 480, pp. 51-70.

Costa, M. F. (1966). Da formação e da expansão da nacionalidade. Boletim Geral do Ultramar, Vol. XLII - 493, pp. 61-122.

Chambers, I (2006). La cultura después del humanismo: historia, cultura, subjetividad. Madrid: Cátedra.

Chambers, I. y Curti, L. (Ed.) (1996). The Post-colonial Question: common skies, divided horizons. London: Routledge.

De las Casas, B. (1989). Brevísima relación de la destrucción de África. Salamanca: San Esteban.

Elias, H. (2004). A emergencia de um espaço de representação: arte pública e transformaçoes urbanas na zona ribeirinha de Belém. On the w@terfront. Nº 6, pp. 43-135.

Elias, H. (2010). A Construção da Fonte Monumental da Alameda Afonso Henriques (19381948) através dos periódicos e do processo administrativo. On the w@terfront, vol. 15, pp.3-34.

Elias, H. y Marques, I. (2012). As últimas encomendas de arte pública do Estado Novo (19651985). On the w@terfront, $\mathrm{n}^{\circ} 23, \mathrm{pp} .5-29$.

Fanon, F. (1999). Los condenados de la tierra. Tafalla: Txalaparta.

Fonseca, M.L. (2008). Imigração, diversidade e novas paisagens étnicas e culturais. En de Matos, A.T. y Lages, M.F.: Portugal: percursos de interculturalidade. Lisboa: ACIDI, I.P. pp. 49-96. 
Foucault, M. (1978). Microfisica del poder. La Piqueta.

Knippschild, S. y Mínguez, V. (2004). “Ceremoniales, ritos y representación del poder”. III Coloquio Internacional del Grupo Europeo de Investigación Histórica. Castelló de la Plana: Universitat Jaume I.

Lefebvre, H. (1974). La producción del espacio. Papers: revista de sociología, (3), 219-229.

Leite, P. P., Henriques, I. D. C., \& Fantasia, A. (2013). Lisboa Cidade Africana: Percursos e Lugares de Memória da Presença Africana. Lisboa: Marca d’ Água: Publicações e Projetos

Macagno, L. (2003). Cidadania e cidade (aventuras e desventuras do multiculturalismo), Espaços \& Debates, São Paulo, Vol. 23, No 43-44, pp.51-59

Malet Calvo, D. (2007). “A ver quem passa” O Rossio. Proceso social y dinámicas interactivas en una plaza del centro de Lisboa. Universitat de Barcelona. http://hdl.handle. net/2445/35227.

Malheiros, J.M. y Mendes, M. (coord.) (2007). Espaços e Expressões de Conflito e Tensão entre Autóctones, Minorias Migrantes e Não Migrantes na Área Metropolitana de Lisboa. Observatorio da imigração de Portugal, www.oi.acidi.gov.pt

Mbembe, A. (2008). Por un entierro simbólico del colonialismo: Imaginario y espacio público en África. Rebelión. http://www.rebelion.org/noticia. php?id=76895

Petit, B. C. (2014). La representación de la ciudad: de la filosofía al pensamiento urbano. Ángulo Recto. Revista de estudios sobre la ciudad como espacio plural, 6(1), 5-20.

Rousseau, J.J. (2011). Textos completos. Buenos Aires: Tecnibook.

Sassen, S. (1999). La ciudad global. Buenos Aires: Eudeba.

Sassen, S., y Pérez, M. Z. (2007). Saskia Sassen: entrevista. Zehar: revista de Arteleku-ko aldizkaria, (62), 16-25.

Soja, E.W. (2008). Postmetrópolis. Estudios críticos sobre las ciudades y las regiones. Madrid: Traficantes de sueños.

Teixeira, M.C. (1993). A história urbana em Portugal. Desenvolvimentos recentes. Análise Social, vol. XXVIII (121), pp. 371-390.

Vasconcelos, C. (2003). Vivienda, territorios de exclusión y nuevas políticas sociales en Portugal. Scripta Nova, Vol VII, nº 146(124). 